\title{
Augmenting natural convection and conduction based solar dryer
}

\section{Chavan, A. ; Sikarwar, A.; Tidke, V.; Thorat, B.}

Department of Chemical Engineering, Institute of Chemical Technology, Nathalal Parekh Marg, Matunga (East), Mumbai-400019, India, Tel:+91-22-33612023/2001

*E-mail of the corresponding author: thoratbn@gmail.com

\begin{abstract}
Solar conduction dryer (SCD) is a unique technology that uses conduction, convection and radiation mechanism of heat transfer making it one of the most efficient drying system. The SCD is one of the most effective piece of equipment's designed indigenously and it has tremendous potential to capitalize in erstwhile nations of tropical and torrid region where there is abundance of solar insolation. SCD, the most cost-effective dryer which runs on no electricity has already made inroads in the global market. In the present study, CFD studies were carried out for a given geometry and the corresponding boundary conditions.
\end{abstract}

Keywords: Solar Energy; Solar Conduction Dryer; CFD modeling. 


\section{Introduction}

Drying is a complex operation involving transient transfer of heat and mass along with several rate processes, such as physical or chemical transformations, which, in turn, may cause changes in product quality as well as the mechanisms of heat and mass transfer. Physical changes that may occur includes: shrinkage, puffing, crystallization, glass transitions and so on [1]. As it is well known, drying is the most energy intensive operation of the industrial processes [2]. Energy efficiency in drying ranges from a low value of under $5 \%$ for the chemical process industries to $35 \%$ for the papermaking operations [1]. Thus, there is strong contention among the researchers around the globe to develop a simplified and low-cost approach that can minimise or nullify the energy requirement through combination of efficient design and optimized process variables.

Keeping these aspects in mind, several researchers have developed different type of solar dryers in last couple of decades to dry food materials as per the local need and indigenous technology. These dryers were based on the heat transfer mechanism of radiation and natural/ forced convection. They can be categorised in three types, such as, integral (direct), distributed (indirect) and mixed mode. In direct type of solar drying, the sun rays are directly incident on material while in indirect type, the air would absorb the heat and transfer it to the material. In mixed mode, the combinatorial heat transfer mechanism plays a crucial role in drying [3]. Thus, based on the above categorization, the following are some of the popular solar dryers in vogue, i.e. Natural convection cabinet dryer, Forced convection indirect dryer, Green house dryer, Solar tunnel dryer.

As described above, these dryers are working on the principle of one or maximum two heat transfer mechanisms. Solar conduction dryer is the first technology in the world that uses all the three modes of heat transfer, viz., conduction, convection and radiation making it one of the most efficient systems [4]. SCD works without the need for electricity and most importantly at zero operating cost, following the three principles of 'A's, i.e. availability, affordability and accessibility [5]. It costs 3-5 times less than the next competing solar dryer and has payback period of 100 days against cost of electricity saving. SCD is recognized by UNEP-Bayer Ag (Germany) as top four global sustainable technologies and by University of Texas-Austin as global leading social venture. US-AID has included SCD in its Feed the future (FTF) program.

Computational fluid dynamics (CFD) is a highly powerful tool to predict the performance and can help us to optimize the dryer geometry under given operating conditions without actually performing too many experiments. Various solar based designs like (a) solar air heater [6-9]; (b) drying systems such as direct, indirect, mixed [10-12] were simulated using computational fluid dynamics CFD modelling helps us to get the detailed inside look 
in the flow field development, temperature distribution [13], humidity profiling and drying time [14].

The objective of the proposed work is not to understand the existing models and compare them, but to make use of these models with certain additional features and incorporate those state equations for all the three modes of heat transfer, which is the major highlight and selling point of the award-winning technology of Solar Conduction Dryer (SCD). Based on the experimental insights and the foregoing literature, CFD model was developed. Here, the results of CFD models based on combinatorial heat transfer mechanism were compared with the experimental findings. Certain alterations to the existing design were possible to be thought about and they were brought fore as an addendum to the design of the existing/ commercial SCD.

\section{Materials and Methods}

\subsection{Drying Equipment}

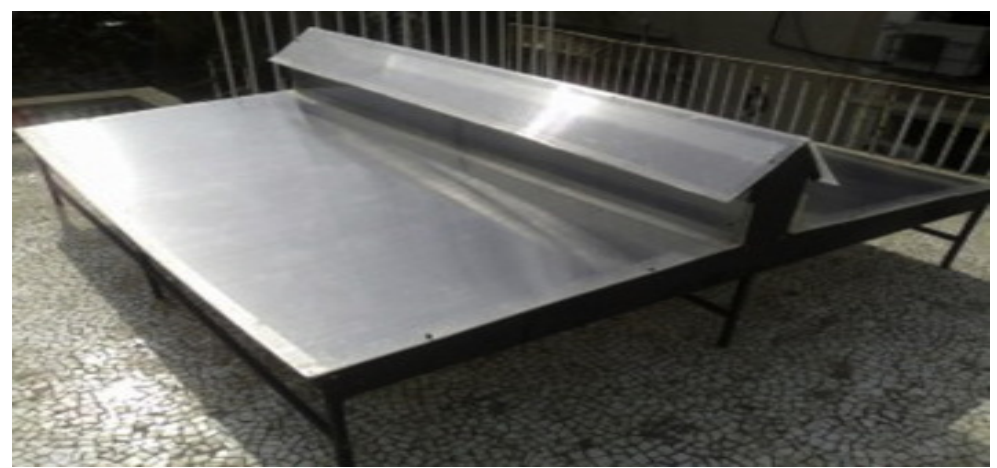

Fig. 1 Solar Conduction Dryer.

The Solar conduction dryer (SCD) is a solar dryer (Figure 1) developed at advanced drying laboratory of Institute of Chemical Technology (formerly UDCT) Mumbai, India. This equipment utilizes solar power in the form of conductive, convective as well as radiation way of heat transfer for drying. The structure of SCD comprises of four drying chambers constructed from hollow sections of stainless steel. The dryer has four drying trays, covering a surface area of $1.04 \mathrm{~m}^{2}$ each. Transparent plastic (Polycarbonate Multiwall Sheet) was used to cover the trays. The trays were coated with black colour special food grade coating, where the products to be dried are placed. The trays were insulated properly so as to minimize the heat losses to the surrounding. A low height air vent to create air current is provided at the middle of the dryer in the horizontal direction which also separates the drying chambers in two portions (parts), as shown in Figure 1. Each portion contains two drying trays. Atmospheric air enters from the front of the trays and it carries away the moisture of the sample through the canopy by means of natural convection. The 
movement of the tray is by sliding them in and out through a designed channel for loading purpose.

\subsection{Model (Governing equations for CFD)}

Mass continuity, momentum, energy and radiation equations were solved to simulate the flow and temperature distribution in the unit. The solar load model available in FLUENT consists of a combination of a solar ray tracing algorithm and a radiation model called surface to surface (S2S). The solar ray tracing algorithm works as the source of the solar heat and the S2S radiation model accounts for the internally scattered energy. The sources for this energy are the surfaces exposed to the solar rays and thus soaked with solar heat energy. Equations are not being reproduced here, as the same could be obtained from Ansys.

\section{Results and Discussion}

SCD was simulated at measured solar radiation flux of $1000 \mathrm{~W} / \mathrm{m}^{2}$. A full-scale 3D simulation of SCD resulted in a symmetric flow pattern. Experimental data also suggested symmetric profile in thermal measurements across the two parts. Hence, half section of the SCD was simulated under the given conditions. Figure 3 shows the flow pattern of air as predicted by the CFD model. It can be seen that the flow is mostly straight without any lateral components. Small circulation zone was observed at the centre of dryer (region where the flow from both the inlets meet and then flows upwards towards the outlet). Here, the flow is predominantly laminar in nature.

\subsection{Flow pattern in solar conduction dryer}

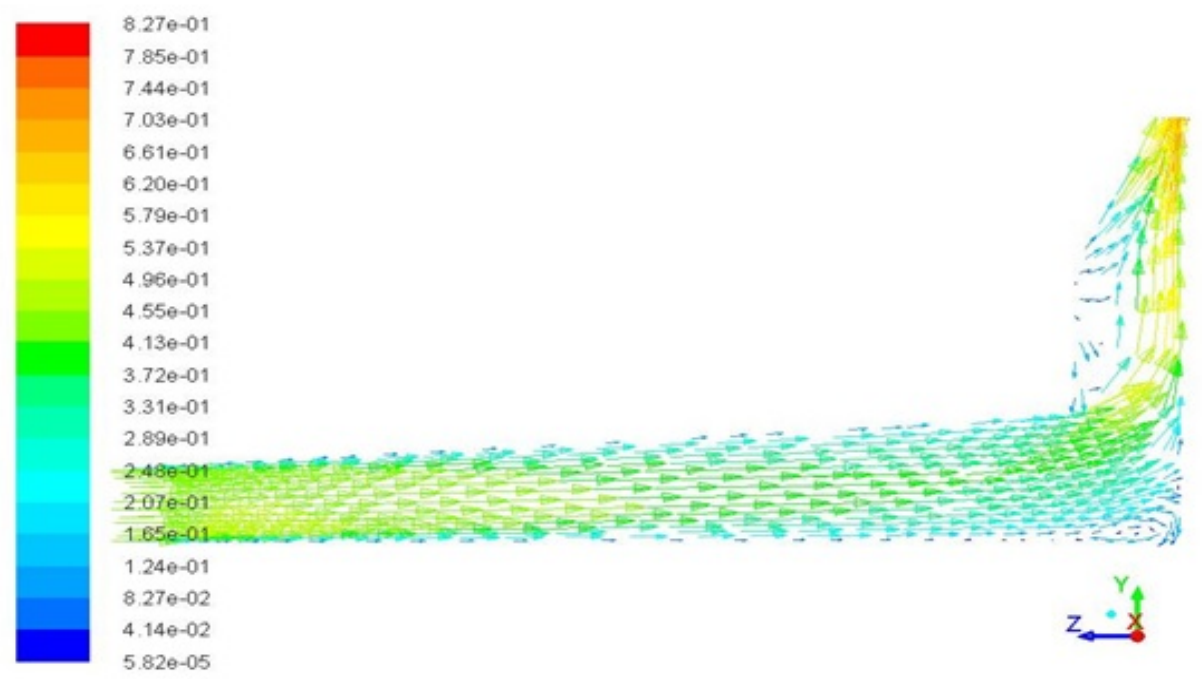

Fig. 2 Flow pattern of air from inlet to centre of dryer. 


\subsection{Comparison between experimental and simulated temperature of bottom plate and top plate of SCD}

The thermal measurement of the bottom plate (Figure 3) indicates sharp rise in the temperature. The temperature remains constant in the dryer section. In the central part, a small dip in the temperature was observed, probably due to the negligible presence of air (hot) adjacent to the bottom plate. As the air gets heated from inlet to dryer section and as soon as it comes at the chimney section, it swirls off through it because of low density. This is very important observation, as it indicates the temperature variation in the dryer in tune with the entry and exit effect of the air. This temperature drop was very well captured in simulation results. Figure 4 compares the predicted temperatures with measured data. It can be deduced that the simulation results are in good agreement with the experimental data.

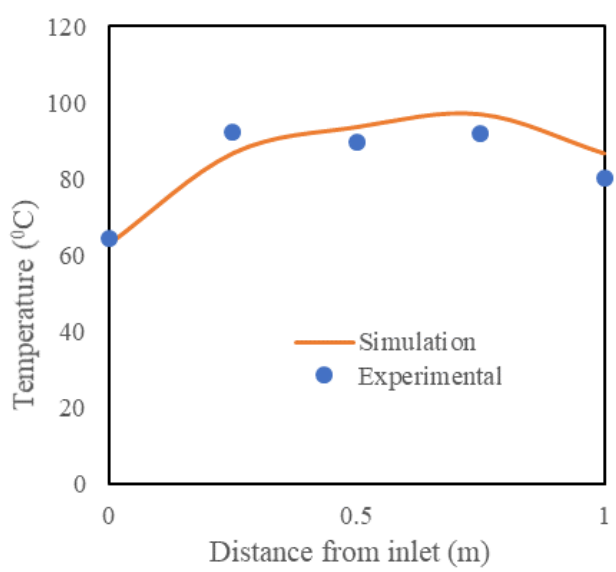

Fig. 3 Comparison of experimental and simulation temperature (Bottom plate).

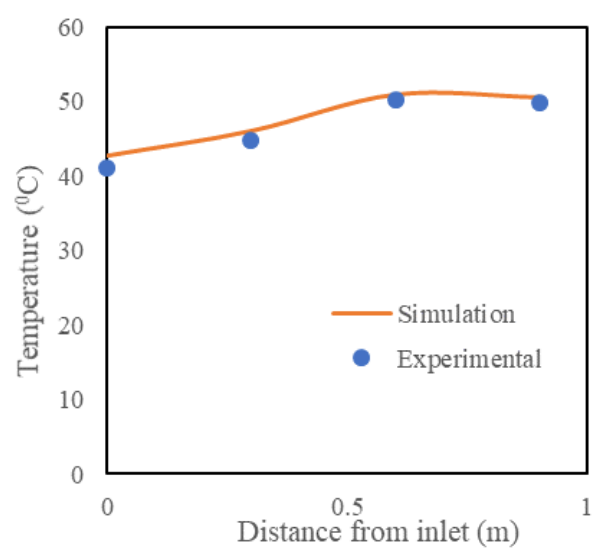

Fig. 4 Comparison of experimental and simulation temperature (Top plate).

\subsection{Proposed design of modified solar conduction dryer (Design 1)}

As per the patented design of solar conduction dryer, there is a loading space gap between the polycarbonate sheet (top plate) and the black coated aluminium plate (bottom plate). The gap is around more than $10 \mathrm{~cm}$ between these two. In order to maximize the utilization of energy and material loading capacity, we can alter the interiors of existing SCD. The modified design (Design 1) will contain an array of plates placed in a staggered manner between the top plate and the bottom plate. The array of plates is designed in such a way that the solar energy reach to the bottom plate. The plates were arranged as shown in Figure 5. Simulations were done described in results and discussion for the staggered plates arrangement. Simulations were performed till the steady results are obtained. These results are as shown in Figures 6-8. 


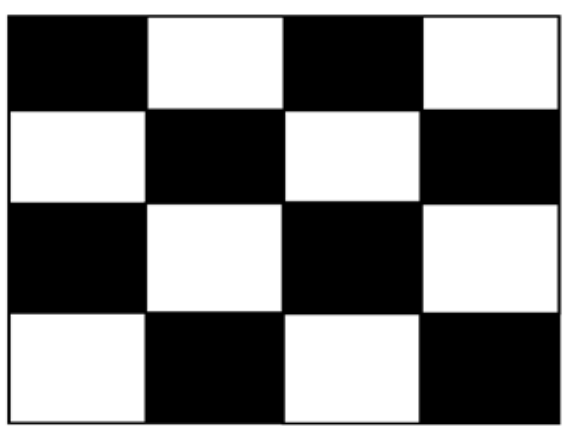

Fig. 5 Intermediate plate structure in modified SCD (Design 1).

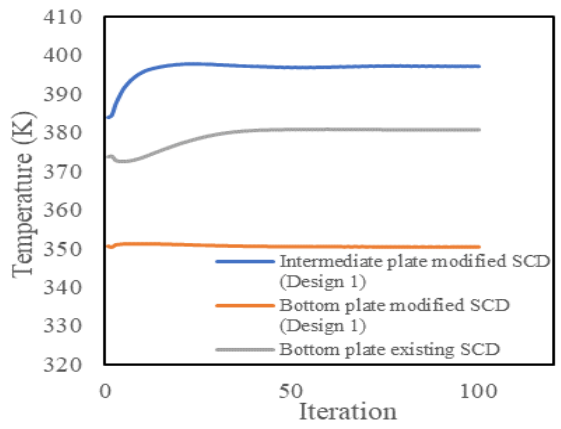

Fig. 7 Area weighted average temperature of bottom plate and intermediate plate in existing and modified SCD (Design 1).

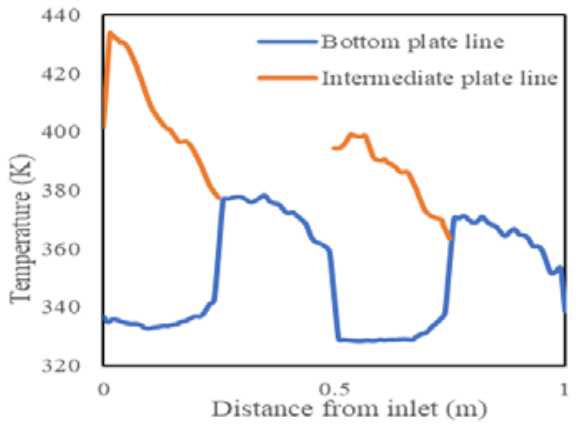

Fig. 6 Temperature profile of intermediate and bottom plate in modified SCD (Design 1).

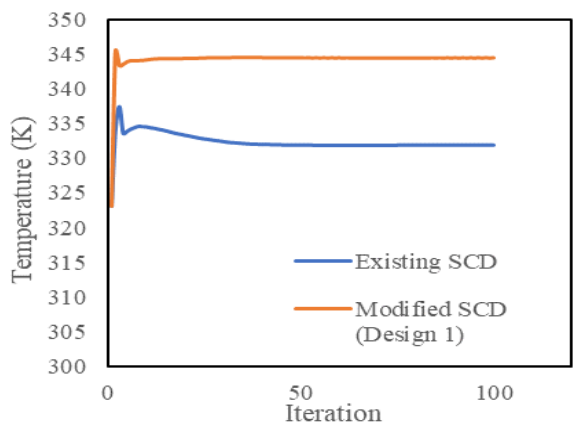

Fig. 8 Area weighted average temperature at outlet in existing and modified SCD (Design 1).

\subsection{Comparison between existing and groove bottom plate SCD (Design 2)}

It was found in the literature that the grooved or corrugated absorber plate creates maximum heat transfer area. There are so many type of grooved plates. So, the idea was that the use of that concept in our case. From the figures 11 and 12, it was found that, there is considerable difference of area weighted average temperature of bottom plate and the outlet air temperature. The use of groove absorber in the place of flat absorber provides a large surface area for heat transfer to the air stream. The convective heat transfer from bottom plate to air increases in this case but the loss is largely compensated by the increased heat transfer to the flowing air [15].

\section{Conclusions}

The CFD model has been successfully developed to predict the temperature of top and bottom plate. The model predictions are in good agreement with the measured data in 
summer as well as winter environmental conditions. CFD simulations of modified solar conduction dryer was also carried out and it gives higher performance. Modified SCD is superior than the existing SCD in terms of outlet air velocity, outlet air temperature, intermediate plate temperature and material handling capacity. The material handling capacity can be increased by as high as $50 \%$. SCD contained groove bottom plate simulations were also done and it was found that there was increase in the outlet air temperature compared to existing SCD.

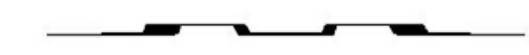

Figure 9: Front view of groove bottom plate (Design 1).

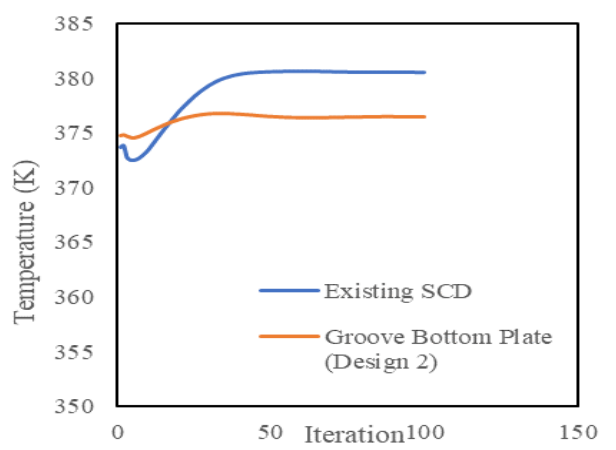

Figure 11: Area weighted average temperature of bottom plate in existing and groove bottom plate SCD (Design 2).

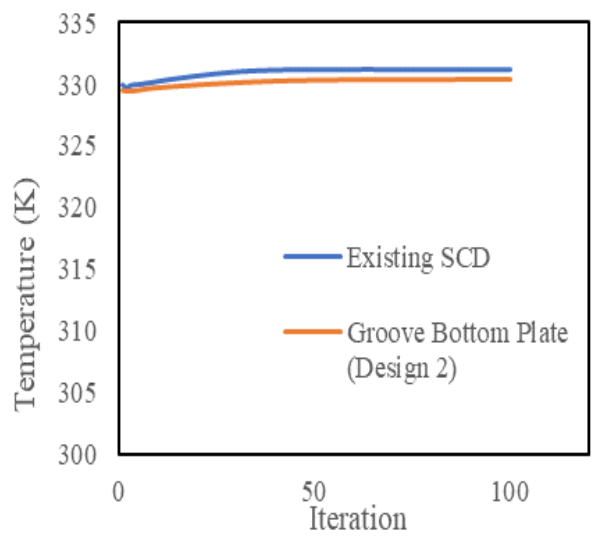

Figure 10: Area weighted average temperature of top plate in existing and groove bottom plate SCD (Design 2).

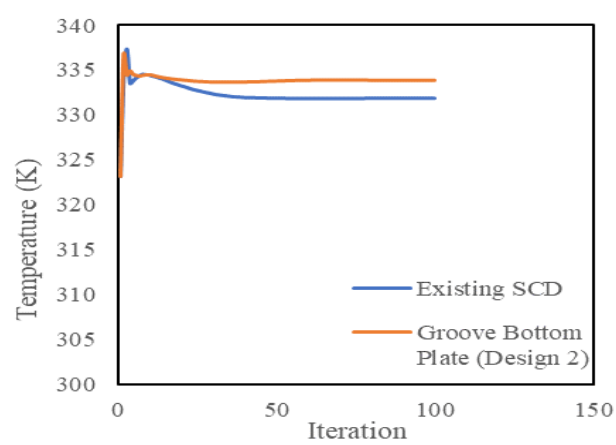

Figure 12: Area weighted average temperature of outlet temperature of air in existing and groove bottom plate SCD (Design 2).

\section{References}

[1] Mujumdar, A. S. Handbook of Industrial drying. 3, Ed. U. S. A.: CRC Press 2006. 
[2] Bennamoun, L. An Overview on application of exergy and energy for determination of solar drying Efficiency. International Journal of Energy Engineering 2012, 2(5), 184194.

[3] Bennamoun, L. Reviewing the experience of solar drying in Algeria with presentation of the different design aspects of solar dryers. Renewable and sustainable energy reviews 2011, 15, 3371-3379.

[4] Tidke, V.; Thorat, B.; Kokate, S. Solar Conduction Dryer with Controlled Radiation. PCT/IN/2012/000843 (2014).

[5] Professor Thorat's personal communication with Professor Arun Mujumdar, 2017.

[6] Yadav, A. S.; Bhagoria, J. L. A CFD (Computational Fluid Dynamics) based heat transfer and fluid flow analysis of a solar air heater provided with circular transverse wire rib roughness on the absorber plate. Energy 2012, 15, 1127-1142.

[7] Boulemtafes-Boukadoum, A.; Benzaoui, A. CFD based analysis of heat transfer enhancement in solar air heater provided with transverse rectangular ribs. Energy Procedia 2014, 50, 761-772.

[8] Singh A.; Singh, S. CFD investigation on roughness pitch variation in non-uniform cross-section transverse rib roughness on Nusselt number and friction factor characteristics of solar air heater duct. Energy 2017, 128, 109-127.

[9] Gawande, V. B.; Dhole, A. S.; Zodpe, D. B.; Chamoli, S. A review of CFD methodology used in literature for predicting thermos-hydraulic performance of a roughened solar air heater. Renewable and Sustainable Energy Reviews 2016, 54, 550 605.

[10] Chauhan, P. S.; Kumar, A.; Tekasakul, P. Applications of software in solar drying systems: A review. Renewable and Sustainable Energy Reviews 2015, 51, 1326-1337.

[11] Prakash, O.; Laguri, V.; Pandey, A.; Kumar, A.; Kumar, A. Review on various modelling techniques for the solar dryers. Renewable and Sustainable Energy Reviews 2016, 62, 396-417.

[12] Romero, V. M.; Cerezo, E.; Garcia, M. I.; Sanchez, M. H. Simulation and validation of vanilla drying process in an indirect solar dryer type prototype using CFD Fluent program. Energy Procedia 2014, 57, 1651-1658.

[13] Norton, T.; Sun, D. Computational fluid dynamics (CFD) an effective and efficient design and analysis tool for the food industry: A review. Trends in Food Science and Technology 2006, 7 (11), 600-620.

[14] Carlescu, P.; Arsenoaia, V.; Rosca, R.; Tenu, L. CFD simulation of heat and mass transfer during apricots drying. LWT- Food Science and Technology 2017, 85, 479486.

[15] Anuradha, A.; Oomen, R. Fabrication and performance evaluation of a V-groove solar air heater. International Journal of Scientific and Engineering Research 2013, 4(6), 2072-2080. 